Louisiana State University

LSU Digital Commons

$1-1-2013$

\title{
Biotechnology for mechanisms that counteract salt stress in extremophile species: A genome-based view
}

\author{
Ray A. Bressan \\ Gyeongsang National University \\ Hyeong Cheol Park \\ Gyeongsang National University \\ Francesco Orsini \\ Alma Mater Studiorum Università di Bologna \\ Dong ha Oh \\ Gyeongsang National University \\ Maheshi Dassanayake \\ University of Illinois at Urbana-Champaign
}

See next page for additional authors

Follow this and additional works at: https://digitalcommons.Isu.edu/biosci_pubs

\section{Recommended Citation \\ Bressan, R., Park, H., Orsini, F., Oh, D., Dassanayake, M., Inan, G., Yun, D., Bohnert, H., \& Maggio, A. (2013). Biotechnology for mechanisms that counteract salt stress in extremophile species: A genome-based view. Plant Biotechnology Reports, 7(1), 27-37. https://doi.org/10.1007/s11816-012-0249-9}




\section{Authors}

Ray A. Bressan, Hyeong Cheol Park, Francesco Orsini, Dong ha Oh, Maheshi Dassanayake, Gunsu Inan, Dae Jin Yun, Hans J. Bohnert, and Albino Maggio 


\title{
Biotechnology for mechanisms that counteract salt stress in extremophile species: a genome-based view
}

\author{
Ray A. Bressan • Hyeong Cheol Park - Francesco Orsini • \\ Dong-ha Oh • Maheshi Dassanayake · Gunsu Inan • \\ Dae-Jin Yun · Hans J. Bohnert • Albino Maggio
}

Received: 4 April 2012/Accepted: 14 July 2012/Published online: 17 August 2012

(C) Korean Society for Plant Biotechnology and Springer 2012

\begin{abstract}
Molecular genetics has confirmed older research and generated new insights into the ways how plants deal with adverse conditions. This body of research is now being used to interpret stress behavior of plants in new ways, and to add results from most recent genomicsbased studies. The new knowledge now includes genome sequences of species that show extreme abiotic stress tolerances, which enables new strategies for applications through either molecular breeding or transgenic engineering. We will highlight some physiological features of the extremophile lifestyle, outline emerging features about halophytism based on genomics, and discuss conclusions about underlying mechanisms.
\end{abstract}

R.A. Bressan and H.C. Park contributed equally to the article.

\section{R. A. Bressan}

Horticulture Department, Purdue University,

W. Lafayette, IN, USA

e-mail: bressan@purdue.edu

R. A. Bressan - H. C. Park - D. Oh · D.-J. Yun - H. J. Bohnert Division of Applied Life Sciences, Gyeongsang National University, Jinju, Korea

R. A. Bressan - H. J. Bohnert

College of Science, King Abdulaziz University,

Jeddah, Saudi Arabia

F. Orsini

Department of Agro-environmental Sciences and Technologies,

University of Bologna, Bologna, Italy

D. Oh · M. Dassanayake $\cdot$ H. J. Bohnert

Department of Plant Biology, University of Illinois

at Urbana-Champaign, Urbana, IL, USA
Keywords Thellungiella . Extremophile species . Genome sequences - Abiotic stress protection . Biotechnology potential

\section{Introduction}

Over the last two decades, the search for superior alleles of key genes for plant stress tolerance has often relied on Arabidopsis thaliana. This plant provided a model that has significantly contributed to advance our mechanistic understanding of plant responses to environmental stresses, although the species itself is not stress tolerant by any imagination (Sanders 2000; Chen et al. 2004). Even so, the rapid development of powerful tools in molecular biology has opened up unprecedented opportunities to explore the genomes of halophytic species, which could provide better model

G. Inan

Institute of Biotechnology, University of Ankara, Tandoan, Ankara 06100, Turkey

H. J. Bohnert

Department of Crop Science, University of Illinois

at Urbana-Champaign, Urbana, IL, USA

A. Maggio ( $\square)$

Department of Agricultural Engineering and Agronomy,

University of Naples Federico II, Portici, Italy

e-mail: albino.maggio@unina.it 
systems in plant salt tolerance research, the stress on which we focus as an example (Inan et al. 2004; Orsini et al. 2010).

There is no straightforward definition of what makes a halophyte. Halophytic lifestyles - in oceans, tidal marshes, salt pans, or in irrigated deteriorated lands-take many shapes. We will focus here on salinity as a causative agent, restricting ourselves to the presence of $\mathrm{NaCl}$, although salinity stress is much more complex in nature (Flowers 2004; Maggio et al. 2006), and similar arguments apply to other types of abiotic stresses.

Most broadly, halophytes on land may be defined as plants that can complete their life cycle in the presence of a salt concentration in the root zone that would kill at least $95 \%$ of higher plant species (Flowers and Colmer 2008). Despite this general and apparently comprehensive definition, an unequivocal classification of halophytes based on both quantifiable growth performance parameters and functional halophytic traits is not available. A partial inventory, compiled by Aronson (1989), classified 1,560 species and 550 genera in 117 families as halophytes. This list refers only to plants with a potential as food, forage, fuel-wood or soil stabilization, and, according to Le Houerou (1993), includes probably only 20-30\% of the terrestrial halophytic flora. Interestingly, approximately $60 \%$ of these species are found in only 13 families. Among those, the Chenopodiaceae contain the largest number of halophytic species (more than 270) followed by Poaceae, Fabaceae, and Asteraceae. All together, these comprise fewer than $5 \%$ of all angiosperm species (Glenn et al. 1999).

Here, we will discuss physiological parameters that are associated with salinity stress tolerance parameters, with particular emphasis on the developmental windows and genetic determinants that appear to mark thresholds in adaptations. In many cases, the salt stress phenotype can be associated with genes that have been revealed by mutagenesis in Arabidopsis and increasingly also from rice (Zhu 2000; Oo and Lang 2005). These two species, or, rather most of their lines and ecotypes, are salt sensitive, but mutations typically will increase sensitivity (Zhu 2000).

Technology in the form of improved DNA sequencing, especially so-called next-generation sequencing (NGS), is beginning to provide genome sequences, which, although they are not complete in an all encompassing sense, nevertheless contain all or nearly all (predicted) coding regions. Unlike Arabidopsis thaliana and Oryza sativa, species with extremophile characteristics include the moss Physcomitrella patens, Populus sp. (poplar) (Rensing et al. 2008; Tuskan et al. 2006) and two close relatives of Arabidopsis: Thellungiella parvula and the salt cress Thellungiella salsuginea (formerly T. halophila) (Deng et al. 2009; Oh et al. 2010; Wang et al. 2010; Dassanayake et al. 2011b; Xie Q, personal communication). The analysis of these genomes, which is only just beginning, indicates several avenues that show a strong correlation with the halophytic lifestyle or, to generalize, identifies gene complexity and structure that seem to reflect different plant habitus and ecological niche. We suggest that the results of comparative genomic studies will initiate breeding and genetic engineering avenues that have not been considered up to now.

\section{The salt tolerance phenotype: how much $\mathrm{NaCl}$ is too much?}

The fundamental physiological strategies by which halophytes cope with saline conditions such as avoidance, evasion and adaptation are also common to glycophytes (Zhu 2001). Tolerance mechanisms specific to halophytes involve a variety of morphological traits, such as succulence or salt glands (Breckle 2002). A tolerance classification system has been set up based on quantitative analyses of growth performances during and after the adaptation of halophytes to salt stress (Flowers et al. 1986). However, there is no unequivocal physiological basis that would allow a clear line to be drawn between glycophytes and halophytes, with the latter having themselves a large degree of variability in terms of growth in the presence of salt. For instance, moderate salt tolerance is found in crops such as sugar beet (Beta vulgaris, Chenopodiaceae), date palm (Phoenix dactylifera, Arecaceae) or barley (Hordeum vulgaris, Poaceae) that can complete their life cycle in concentrations of $5 \mathrm{~g} \mathrm{l}^{-1}$ of total dissolved salts (TDS), or equivalent to approximately $80 \mathrm{mM} \mathrm{NaCl}$ (Ayers and Westcot 1985). In contrast, extreme halophytic species such as Salicornia bigelovii (Chenopodiaceae) generate remarkably high yields even when the soil solution exceeds $70 \mathrm{~g} \mathrm{l}^{-1}$ TDS (1,300 mM NaCl) (Glenn et al. 1985, 1991). Most glycophytes relevant to agricultural production have been ranked based on their yield reduction per unit in salinity relative to the maximum yield obtained under nonsaline conditions (Maggio et al. 2007). A similar systematic classification does not exist for halophytes, to a large part due to the many degrees of adaptation that in the past had been expressed by distinctions between facultative and obligatory halophytic species. It is also important to point out that none of the definitions of halophytes (Kreeb 1974; Flowers and Colmer 2008) takes into account developmental phases with different salinity tolerance thresholds, or differential organ development in response to salinity. Such information is often also missing for glycophytes, including information on the relative sensitivity of shoot versus root, which can have important adaptive and agronomic implications (Dalton et al. 2000; Maggio et al. 2007). An increased shoot/root ratio at high salinity has been reported for Atriplex species, whereas a decrease has been found in Australian salt-marsh plants (as well as in the 
glycophytes maize and soybean) (Redondo-Gómez et al. 2007).

\section{The emergence of mechanisms}

Even though traits associated with salt tolerance of halophytes have been extensively studied, as documented by the volume of publications, it has been difficult to define salt tolerance in morphological, physiological or molecular terms. The accumulation of $\mathrm{Na}^{+}$in a controlled fashion, as a driver for water uptake against low external water potential, is probably the mechanism that has early on, and subsequently most often, been identified as a requirement of the halophytic lifestyle (Flowers et al. 1977; Ungar and Pfeiffer 1991; Bohnert and Cushman 2000). Much attention has been given to the uptake and distribution systems of ions that can be toxic, and this has also been the major feature in attempting the classification of halophyte types. The discrimination of $\mathrm{Na}^{+}$versus $\mathrm{K}^{+}$, often credited as a major feature of halophytism, is an important though not sufficient determinant. Salicornia europea and Suaeda maritima are considered true $\mathrm{Na}^{+}$accumulators, whereas the equally tolerant Puccinellia distans possesses a strong selective capacity of $\mathrm{K}^{+}$versus $\mathrm{Na}^{+}$at both low and high salinity (Tarasoft et al. 2007). Degrees of ion selectivity have been reported for halophytic and non-halophytic Chenopodiaceae (Flowers and Colmer 2008). Differences in $\mathrm{Na}^{+}$accumulation among dicotyledonous and monocotyledonous halophytes have also been documented (Greenway 1968) and used to distinguish, on a highly inconsistent scale, inclusion versus exclusion strategies to cope with a highly saline environment. In fact, early observations on the level of accumulation of $\mathrm{NaCl}$ into the shoots led to the classification of dicotyledonous halophytes as "includers", since they accumulated more $\mathrm{NaCl}$ in shoot tissues compared to monocotyledonous plants, which were then termed "excluders" (Greenway 1968). Subsequently, this distinction was clarified by Greenway and Munns (1980), who recognized that monocots (mostly grasses) still use leaf $\mathrm{Na}^{+}$accumulation for osmotic adjustment, yet apparently to a lesser extent compared to halophytic dicots. Further studies with Atriplex canescens, however, demonstrated that the growth rate of different accessions was strongly correlated with their capacity for accumulating $\mathrm{Na}^{+}$and negatively correlated with their capacity to accumulate $\mathrm{K}^{+}$, highlighting remarkable interspecies variability (Glenn et al. 1992; Mata-González et al. 2001).

It is notable that almost no studies have exploited the use of genetics, either through crosses and segregation analyses, or by mutagenesis and selection systems, with very few exceptions (Cushman and Bohnert 1999;
Cushman 2001; Munns 2002). Importantly, the species used were either not halophytic or their other features precluded efficient identification of genetic loci involved in coping with high external $\mathrm{Na}^{+}$levels (Munns 2002).

Specific anatomical features may be responsible for salt tolerance in halophytes. Salt glands are typical morphological adaptations in black mangroves (Avicennia spp.), which excrete excess salts onto the leaf surface, yet this seems not to be a critical mechanism for the salt-tolerant red mangroves, Rhizophora spp. (Popp 1995; Popp and Albert 1995). Salt glands (Liphschitz and Waisel 1982; Balsamo and Thomson 1993, 1996) and salt bladders (Schirmer and Breckle 1982; Freitas and Breckle 1992; Adams et al. 1998; Orsini et al. 2011) may contribute by excreting up to and exceeding $50 \%$ of the salt entering the leaf to cope with transitory imbalances of tissue $\mathrm{NaCl}$ (Glenn et al. 1999). In desert halophytes such as Atriplex, salt excretion may also have secondary adaptive functions (e.g., light reflection) that may protect the photosynthetic machineries (Osmond et al. 1980).

\section{Ion accumulation and export}

Succulence or reduction in leaf water content may function to dilute excess $\mathrm{NaCl}$ in leaf tissues (Kramer 1984) or to adjust the amount of $\mathrm{NaCl}$ necessary to establish a favorable osmotic flux (Glenn and O'Leary 1984; Glenn 1987). Regulation of water flux through the plant has emerged as an important component of salinity tolerance in halophytes. Developmental regulation of stomata density, size and closure has been functionally associated with stress tolerance (Farnsworth 2004; Yang et al. 2005). This trait has not been systematically analyzed for halophytes. It tends to be linked to excluder species. Halophytes in general exhibit reduced stomatal conductance compared to glycophytes, with transpiration further decreased as the exposure to salinity increases (Flowers and Yeo 1995; Serrano 1996). In fact, several halophytes, including the well-studied model Mesembryanthemum crystallinum, are capable of CAM metabolism that is stress induced and developmentally controlled to limit stomatal water loss (Adams et al. 1998). Although there have been several attempts to match morphological and physiological characters to specific halophyte habitats or growth strategies, the classification systems that have been developed still cannot predict degrees of halophytism.

\section{A comparative physiological study}

A recent study (Orsini et al. 2010) compared 11 wild relatives of Arabidopsis thaliana with respect to differences 


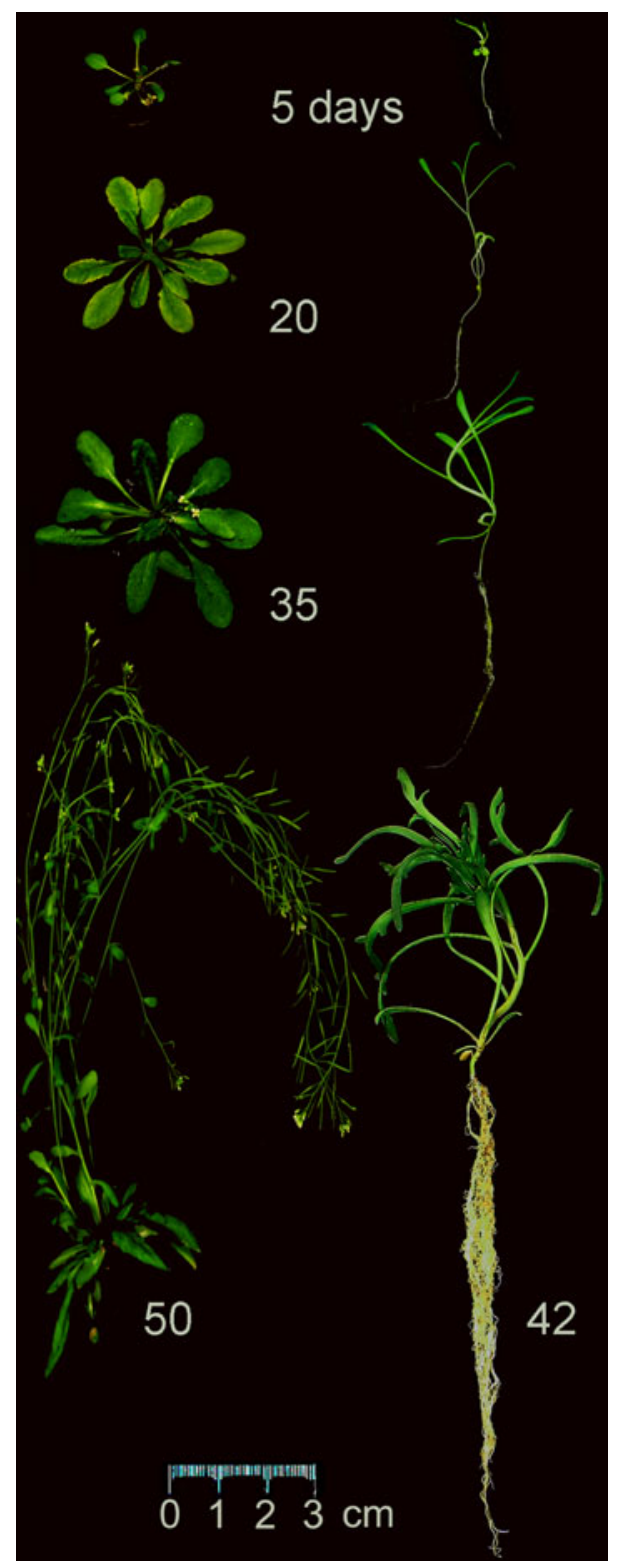

Fig. 1 Plants of A. thaliana (Col-0) and $T$. parvula at different growth stages. Plants were grown in perlite and pumice, in a growth chamber with a photosynthetic photon flux of $500 \mathrm{mmol} \mathrm{m}^{-2} \mathrm{~s}^{-1}$ from cool-white fluorescent lamps and a 16-h light/8-h dark photoperiod. Plants of T. parvula at 42 days were grown on Turface ${ }^{\circledR}$ calcined clay (Profile Products, Buffalo Grove, IL, USA), in a growth chamber with a photosynthetic photon flux of $250 \mathrm{mmol} \mathrm{m}^{-2} \mathrm{~s}^{-1}$ from cool-white fluorescent lamps and a 16-h light/8-h dark photoperiod

in growth, water transport properties, and ion accumulation to identify Arabidopsis-relative model systems (ARMS) that could serve as the genetic basis to advance our understanding of halophyte-specific mechanisms. It has been demonstrated that $T$. parvula (Fig. 1) has a true halophytic habitus comparable to Thellungiella salsuginea, a species that has been more extensively studied. The analysis presented by Orsini et al. (2010) added phenotypic markers that allowed us to place several close Arabidopsis relatives with halophytic characters and an extremophile lifestyle into a framework for further studies. The halophytic habitus of these species (Fig. 2a, b) was associated with several morpho-physiological traits that have so far been largely underexplored in salinity tolerance research, including the ability to control transpiration water loss versus growth, reduced daily transpiration rates, and differential control of $\mathrm{Na}^{+}$versus $\mathrm{K}^{+}$fluxes (Volkov and Amtmann 2006). Among these qualities, the ability of these plants to maintain a close to constant root-to-shoot ratio at increasing salinity appears to be critical (Fig. 2c, d). A significant drop of the root-to-shoot ratio in Arabidopsis, due to a relatively higher sensitivity of roots versus shoots to salinity, appeared to coincide with overall saltinduced growth inhibition. We do not know how this and other morphological adaptation traits (see also the higher stomatal density in $T$. parvula and $T$. salsuginea compared to A. thaliana; Orsini et al. 2010) are functionally linked to the overall metabolic program that distinguishes halophytes from glycophytes. However, we imagine that the experience gained over the last decade in developing genetic systems based on insertion mutagenesis and the application of recently developed high-throughput DNA sequencing technologies (Oh et al. 2010; Dassanayake et al. 2011b) will rapidly lead to results from which we can begin to understand the evolutionary patterns that are at the basis of halophytic adaptations to extreme environments. Genomics, it seems to us, will become the tool that can bridge the gap that lets us go from correlative to mechanistic understanding.

\section{Genomics takes center stage}

The complexity of the halophytic lifestyle is best addressed by exploiting and further developing those genetic resources that can fit the principle of effective ARMS. Together with the ongoing generation of salt cress mutants with disruptions in osmotic regulatory properties, comparative analysis with other ARMS should be started. We argue that, for $T$. salsuginea (salt cress) and $T$. parvula, additional phenotypic and physiological tolerance markers should be established to go along with exhaustive transcriptome profiling to accompany the full genome sequence models that already exist for both Thellungiella species (Dassanayake et al. 2011b; Xie Q., personal communication). Comparative analyses and the juxtapositioning of responses to salinity by Arabidopsis and species in the category of ARMS will bring about an understanding of the mechanisms and will establish links between diverse tolerance traits and the genetic bases that are responsible for these characteristics (Bressan et al. 2001). These 
Fig. 2 Effects of $\mathrm{NaCl}$ on shoot fresh weight $(\mathbf{a}, \mathbf{b})$ and root:shoot ratio $(\mathbf{c}, \mathbf{d})$ of

T. parvula, T. salsuginea and

A. thaliana (Col-0). Plants were grown in Perlite and Pumice in a growth chamber with a photosynthetic photon flux of $500 \mu \mathrm{mol} \mathrm{m}^{-2} \mathrm{~s}^{-1}$ from coolwhite fluorescent bulbs and a 16-h light/8-h dark photoperiod. $\mathrm{NaCl}$ was added incrementally to the irrigation water every 5 days starting from 15 days after sowing, to a final concentration of $150 \mathrm{mM}$. Plants were harvested every 5 days until day 55. Gray circles $T$. parvula, white circles T. salsuginea, black circles A. thaliana. Values are mean $\pm \mathrm{SE} ; n=9$
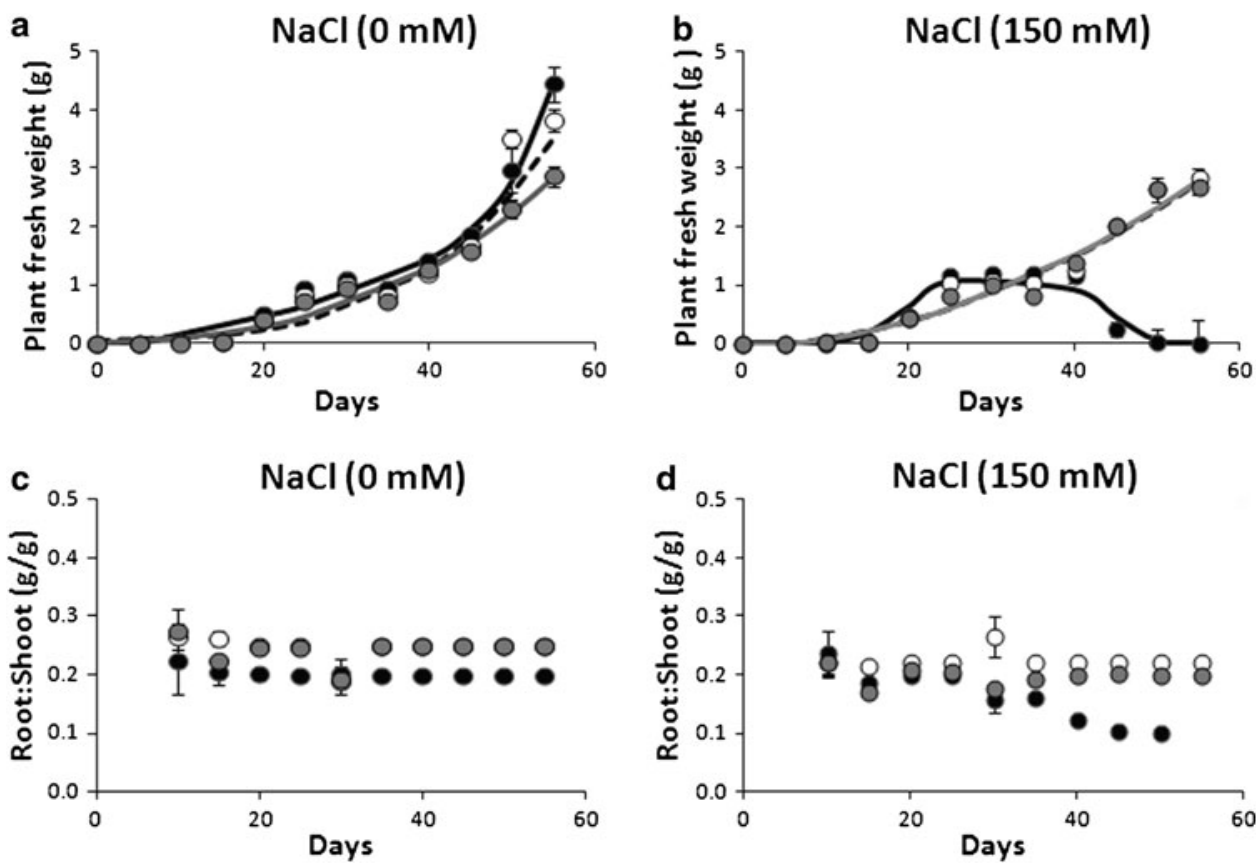

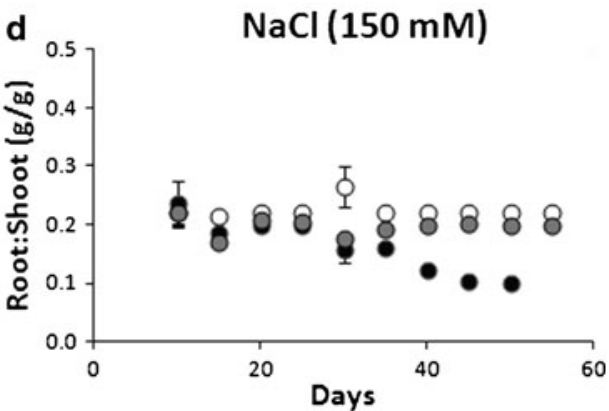

genetic/bioinformatics comparative analyses will be greatly enhanced by the addition of genome sequence information of additional ARMS with established extremophile phenotypes.

Several studies over the past decade have produced enigmatic results that can, with genomic hindsight, be rationalized. For example, a comparison of the transcription programs of two rice lines (salt-tolerant Pokkali and sensitive IR29) showed that both lines induced a very similar set of genes after a salt shock, but Pokkali terminated expressing this set of genes within a few hours and switched on genes in metabolism and development that are not indicative of severe stress responses. IR29 continued to express genes that have been labeled stress-inducible after a 150-mM NaCl treatment and died (Kawasaki et al. 2001). Another study using rice microarrays with $\sim 55-\mathrm{K}$ probes compared a salt tolerant line FL478 with the sensitive IR29, revealing larger numbers of genes regulated in IR29 by salt stress, as well as different regulation of genes in flavonoid biosynthesis pathways and cell wall restructuring between the two lines (Walia et al. 2005). Similarly, a comparison of $A$. thaliana Col-0 and salt cress saltdependent transcription programs indicated a large overlap in the types of genes induced, repressed or unaltered during salt stress treatments. The significant difference was that salt cress showed responses only at much higher salt levels than Arabidopsis and rapidly went back to a new state (Gong et al. 2005). One tentative conclusion in interpretation of these differences in response capacity was that there did not appear to be a battery of magical stress response and protection genes, that these close relatives are distinguished by degrees of sensitivity by which different outcomes were orchestrated. However, the outcome was still determined by a common set of genes.

\section{Genome and transcriptome sequences}

The genome sequences for $T$. salsuginea and $T$. parvula are available in the form of chromosome models (Dassanayake et al. 2011b; Xie Q., personal communication, http:// thellungiella.org/, http://www.phytozome.net/thellungiella. php). In both genomes, the amount of transcripts and deduced amino acid sequences exceeds the number of authentic transcript units by a few hundred putative additional genes. In both species, the numbers of genes and size of gene space are similar; differences exist mainly in the content of repetitive DNAs, which, in $T$. parvula, are less than $15 \%$ of the genetic space, while they amount to more than $50 \%$ in the case of $T$. salsuginea. A detailed analysis and comparison between the A. thaliana and $T$. parvula genomes identifies the "movement" of centromeric regions that accompanied the evolution of crucifers to result in a variable number of chromosomes (Mandáková and Lysak 2008; Dassanayake et al. 2011b). Other distinguishing aspects in genome organization include the proliferation of different transposable elements, and the emergence of species-specific putative reading frames for which no function is known in $T$. parvula or A. thaliana. In addition, sequences upstream of coding regions, for which functions have been determined in A. thaliana, are to a very large percentage different in $T$. parvula. It seems that gene 
control elements have evolved in a different and novel way, and those differences appear to be a factor in how T. parvula copes with the abiotic stresses to which it is exposed (Oh et al., in preparation). A preliminary analysis of the T. salsuginea genome suggests that both Thellungiella species share the differences in promoter structure.

The notion about the potential importance of copy number variation $(\mathrm{CNV})$ in shaping ecological adaptation and lifestyle has recently been substantiated by more detailed analyses of differences between Arabidopsis and Thellungiella; differences first in how the SOS system is engaged during stress (Oh et al. 2009; Dassanayake et al. 2011a) and by monitoring differences in genome structure not only at the macro level but also in the details of the uptake systems of sodium ions (Oh et al. 2010; Dassanayake et al. 2011b; Ali et al. 2012; Hong et al., in preparation).

One outstanding feature emerging from a comparison of the Arabidopsis and Thellungiella genome sequences concerns gene content, especially the number and type of gene duplications. For example, comparable numbers of tandem duplication events accumulated during the evolution of Arabidopsis and Thellungiella. What is dramatically different are the type of genes that have become, or have been retained as, duplicated sequences, and the number of genes that have been lost or failed to become duplicated, as exemplified by the different GO profiles of genes in species-specific tandem duplicated arrays between A. thaliana and T. parvula (Fig. 3a). Thellungiella added or retained after (random) duplication genes that are relevant to stress management and survival under abiotic stress, while duplications in the Arabidopsis genome focus on biotic stress defenses (Cannon et al. 2004; Dassanayake et al. 2011b). Further differences between A. thaliana, and T. parvula are observed when GO enrichment for transcript expression abundance is considered between orthologs (Fig. 3b).

A detailed comparison of selected genomic DNA regions in A. thaliana, T. salsuginea and T. parvula provided confirmatory results (Oh et al. 2010). First, an analysis by quantitative PCR revealed that, in a syntenic stretch of DNA in both A. thaliana and $T$. parvula, a number of genes showed higher expression under control conditions in $T$. parvula and a delayed but stronger induction of the genes at very high $\mathrm{NaCl}$ stress. Seemingly, expression strength and response threshold distinguish the two species. Even more revealing was the strong divergence in promoter structure between Arabidopsis and both Thellungiella species for the crucial salinity tolerance gene SOS1 (Oh et al. 2010). In both Thellungiella species studied so far, SOS1 shows very different regulation when compared with A. thaliana. SOS1 and the entire SOS pathway constitute a critical component for salt stress a GO Biological Process

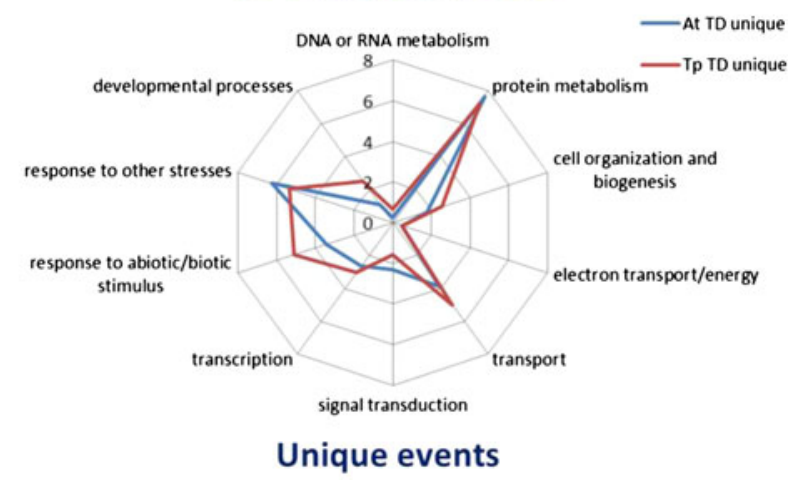

b GO Molecular Function

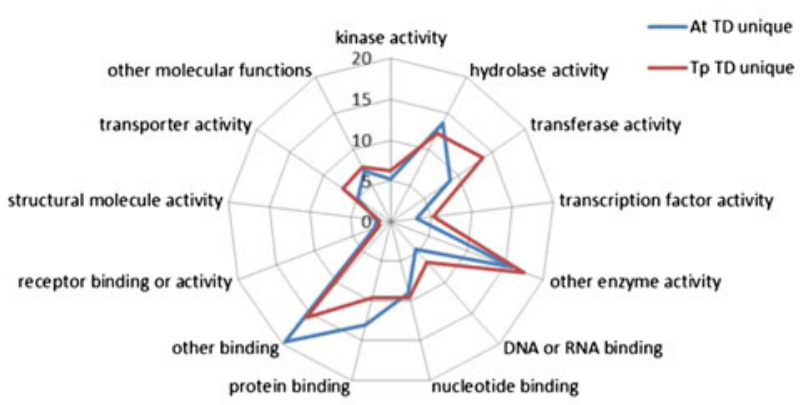

Unique events

Fig. 3 Comparison of GO profiles in genomes and transcriptomes of Arabidopsis thaliana and Thellungiella parvula. a Distribution of TAIR GO slim-categories of genes in tandem duplicated arrays unique to either $A$. thaliana (At) or $T$. parvula (Tp) genomes. $Y$ axes show the percentage of each categories per total number of genes in unique tandem duplicated gene arrays, which are 1,429 and 1,424 for At and Tp, respectively (modified after Dassanayake et al. 2011b). b GO enrichment in basal transcript level for high CNV. A. thaliana $(3,459)$ and $T$. parvula $(3,601)$ highly abundant transcripts $(p<0.5$ with FDR <0.05) were selected out of 19,935 orthologs for GO enrichment analysis against the total GO assignments for the A. thaliana genome as a background. Only significant enrichment for GO 'Molecular Function' is included for each transcriptome $(p<0.01$ and FDR $<0.05)$

adaptation. The activity of the $\mathrm{Na}^{+} / \mathrm{H}^{+}$antiporter SOS1 is regulated through protein phosphorylation by the SOS2/ SOS3 kinase complex which converts inactive SOS1 to an active form (Bertorello and Zhu 2009). In both Thellungiella species, SOS1 and SOS2 transcript expression seems to be regulated very differently from the regulation in A. thaliana. Both genes are highly expressed in the absence of salinity stress, while stress leads to further increases in steady-state transcript amounts (H. Hong, and D.H. Oh, unpublished).

A second difference appeared, unexpectedly, in comparing the $5^{\prime}$-UTR regions between the three species. Both Thellungiella species are characterized by a high C/T-rich stretch within 100 nucleotides of the translation initiation codon, and in both Thellungiella species, a stable 
stem-loop structure can form immediately upstream of the ATG codon. Further investigations showed that both features are found in other SOS1 genes of other halophytes, and are present only in halophyte SOS1 genes (Oh et al. 2009, 2010; Dassanayake et al. 2011b).

At present, such observations may be viewed as inconclusive or anecdotal unless they are be backed by additional data. However, it can be pointed out that the higher transcriptional expression of genes in a species, line, or ecotype must be viewed as akin to a phenomenon that has recently attracted much attention. The term for this phenomenon, copy number variation (CNV), is applied to both gene copy number in a genome as well as to transcript abundance, both of which, on first principles, should increase protein amount. In fact, $\mathrm{CNV}$ has been associated with line differences in animal systems, underlying medically relevant symptoms (e.g., Kato et al. 2010; Waszak et al. 2010). CNV has also been invoked as a factor distinguishing maize from its non-domesticated relatives (Swanson-Wagner et al. 2010).

The case for CNV has been strengthened by the recent completion of the genome sequence of Thellungiella parvula, for which a first draft sequence has been published (Dassanayake et al. 2011a). A second version of T. parvula genome annotation is now available (http://thellungiella. org/data/). The first draft genome sequence and annotation of Thellungiella salsuginea have been prepared by two groups (Xie Q., personal communication; http://www.phytozome. net/thellungiella.php).

Preliminary comparison of $T$. parvula and T. salsuginea with their non-halophyte relative $A$. thaliana identified $\mathrm{CNVs}$, in genome and transcriptome levels, of genes that are related to especially stress tolerance (Dassanayake et al. 2011b; Ali et al. 2012; Hong et al., in preparation). In addition to the shared functional classes in highly abundant transcripts, in the GO molecular function, transcription factor activity is enriched in $T$. parvula, while the category phosphatases activity is slightly higher in A. thaliana (Fig. 3b).

Higher basal level expressions of stress-related genes often coincide with genomic structural variations, such as tandem duplications and translocation duplications (Hong et al., in preparation). This confirms the hypothesis that assumed long ago the evolution by gene duplicationoriginally stated by Susumu Ohno (1970)—as a major driver of evolutionary changes. Duplications followed by sub- and neo-functionalizations of one of the duplicated genes appear as major mechanisms of evolutionary niche adaptations. For example, genes encoding HKT1, a Na ${ }^{+} /$ $\mathrm{K}^{+}$transporter, are tandemly duplicated in $T$. parvula and T. salsuginea. HKT1 is a single gene in A. thaliana. The duplicated copies showed both sub- and neo-functionalization in their gene expression pattern and protein functionality. One of the duplicated copies includes
Thellungiella-specific mutation of two amino acids near the second pore domain, which changed the transporter to favor $\mathrm{K}^{+}$over $\mathrm{Na}^{+}$(Ali et al. 2012). The overall expression levels of these copies are dramatically higher in both Thellungiella species than in A. thaliana (Ali et al. 2012; Hong et al., in preparation). Other examples of known stress-related genes that are duplicated in Thellungiella but not in Arabidopsis include genes encoding AVP1, NHX8, MYB47, CBL1O and KEAl (Dassanayake et al. 2011a). Many of them show dramatically higher basal-level gene expression in Thellungiella than in Arabidopsis (Hong et al., in preparation).

It is noteworthy that these CNVs did not originate from whole genome duplication (WGD) events that most crucifers, including Thellungiella and Arabidopsis, experienced at least three times (Franzke et al. 2011). Thellungiella and Arabidopsis diverged after the most recent WGD event (Mandáková and Lysak 2008; Oh et al. 2010; Dassanayake et al. 2011a). Our initial observation on Thellungiella and Arabidopsis gene duplications confirms other studies that WGD resulted in enriched retention of genes involved in regulatory roles and higher numbers of protein-protein interactions, while tandem duplications tended to amplify genes encoding membrane proteins and enriched in responses to environmental simuli (Freeling 2009; Rodgers-Melnick et al. 2012). In both species, tandem duplications were enriched in categories receptor and transporter activities, and underrepresented with respect to transcription factors, DNA/RNA binding and structural molecule activities (Dassanayake et al. 2011a).

In the analysis of the Thellungiella genomes, which is just beginning, one important aspect for future studies will be to find how the expression characteristics may have changed with respect to timing of expression and condition, and tissue or cell specificity. Especially, higher basal level expression of stress-related genes, even without stress, is a recurrently observed pattern distinguishing Thellungiella and Arabidopsis (Oh et al. 2009, 2010; Ali et al. 2012; Hong et al., in preparation). An exhaustive comparison of the basal-level transcriptomes between the two species will identify genes, of as yet unknown functions, potentially responsible for the phenotypic differences between the two species. Identification of regulatory elements and other genomic structural variations correlated with the observed differences in gene expression strength will reveal the evolutionary mechanism leading to the adaptation of a species to survive in extreme environments.

\section{Towards applications}

Until very recently, comparisons of plant genome sequences had to deal with species of widely different 
evolutionary histories-Arabidopsis to Oryza, poplar or Physcomitrella (a moss) are examples. Gaps in our knowledge about the evolution of extremophile lifestyles have long existed. Only the availability of the Thellungiella genome sequences has made it possible to view different lifestyles in close relatives and to begin to understand the meaning of differences in gene number, gene type, and gene expression. This ability from comparative genomics will also help in understanding the structures of other species' genomes-Oryza, Brachypodium, Pennisetum, Zea, Triticum and Hordeum are examples. While these species in the Poaceae are related, it must be taken into account that they have been intensively manipulated over the last 10,000 years of agricultural practice (Rindos 1987; Allaby et al. 2008). At the other extreme are sequences of the many A. thaliana accessions (also termed ecotypes) that have been described and the genomes of different Arabidopsis species, such as A. lyrata (Hu et al. 2011; Cao et al. 2011). The comparison between $A$. thaliana and $T$. parvula and also the comparison with $T$. salsuginea (Q. Xie, personal communication) will provide a very different viewpoint and unprecedented opportunities not simply for comparative genomic studies but-even more importantly-for the future of crop improvement.

It is quite clear that the Thellungiella genome sequences signify evolutionary solutions of adaptation to an extremophile lifestyle. We consider this view and statement justified by pointing to the many duplicated genes with relevance to stress defenses. In fact, such a statement could equally be applied to, for example, poplar. Its genome includes, for example, a higher number of aquaporin genes than are seen in other sequenced plant genomes, and the gene complement for cell wall functions is also high.

The question then is about whether having available genome sequences of close relatives with different ways of environmental adaptation ("lifestyle") means that they are significant messengers. Can genomes tell how, for example, abiotic stress-tolerant crops may be generated? Can we begin to understand the mechanisms of 'tolerance' acquisition from gazing at genome sequences?

One starting point can be the recognition that the 25,000-30,000 genes in angiosperm genomes are omnipresent. There exist order-, family- and species-specific genes in addition. Here, we face a problem, because these specific genes are absent from the Arabidopsis genome and their putative or possible functions are simply conjecture. However, the vast collection of Arabidopsis stress-relevant mutations that exist indicate the existence of conserved mechanisms about how to deal with abiotic stresses, and these genes exist in many or all higher plants. We consider the retained duplication events and expression characteristics in the Thellungiella species a fair representation of the genetic makeup of a stress-tolerant, in particular a salt stress- tolerant, way of life. In a sense, we have known about meaningful tolerance mechanisms for a long time, from many studies, but all glimpses of genes, their functions, and the mechanisms could not be merged into a coherent picture.

Gene duplications and high or low expression alterations in gene control that together signify $\mathrm{CNV}$ are at the basis of tolerance (Kvitek et al. 2008; Conrad et al. 2010; Dassanayake et al. 2011a; Waterhouse et al. 2011). That leads to a question about transgenic alterations to, it seems, dozens of genes, mainly transcription factors that respond to different hormonal stimuli, by which hundreds of metabolic genes might be controlled to accomplish stress tolerance. These transcription factors would have to be engaged in a condition-specific way, and one problem could be that multiple inputs, e.g., high temperature and stomatal control, might have to be dealt with. Another level of complexity is provided by the more recent studies showing that stresses can have consequences in chromatin accessibility and activity, and showing the prevalence of small interfering RNAs that generate a different level of complexity (Ito et al. 2011; Luo et al. 2012).

For salinity stress tolerance breeding, or at least increased relative tolerances, another avenue is opening up. For many crop species, wide crosses between significantly different breeding lines or closely related species, e.g., domesticated and wild Hordeum sp., exist. In the thousands of lines from these crosses will be individuals that contain alleles for known stress tolerance-enhancing genes-either duplications or genes with altered expression characteristics. Quantitative RT-PCR approaches, or, even better, RNA-seq approaches, may be used to find those individuals. If, out of a population of thousands, 100 plants are identified, crosses can be made that lead to a pyramiding of desired traits in a relatively short time.

Looking beyond the salinity stress problem on which we have focused, the rapidity with which new genome sequences become available foreshadows the immediate future and, we think, a fundamental change in how crop breeding will be approached. The expansion of genome sequencing to non-model species has also opened doors for orphan crop improvement where these are staple food sources in some of the world's poorest regions. These crops are often grown in marginal lands characterized by abiotic stresses. Genome comparisons between extremophile genomes and the recently released orphan crop genomes for cassava and pigeonpea (Cajanus cajan) can lead to accelerated identification of genetic markers for molecular plant breeding or underlying conserved stress-tolerant strategies that can be important in crop improvement (Varshney et al. 2011; Prochnik et al. 2012).

Evolution has generated plants that thrive in very hostile environments. These extremophiles are relatives, often close relatives, of traditional crops. Their contrasting 
lifestyles provide clues to the ease with which genome sequences and global expression profiles can be obtained to open an entirely new road for crop breeding. Our-still ongoing-comparisons of the Thellungiella-Arabidopsis pair of species suggest that genome sequence and transcription control can predict the environment in which a species will succeed.

Acknowledgments We thank Hyewon Hong (GNU, Korea) and Q. Xie (Chinese Academy of Science, Bejing, China) for permission to refer to unpublished data. This work was supported by the World Class University Program (Grant No. R32-10148), funded by the Ministry of Education, Science, and Technology, and the Next-Generation BioGreen 21 Program (Grant No. PJ008025), Rural Development Administration, Republic of Korea.

\section{References}

Adams P, Nelson DE, Yamada S, Chmara W, Jensen RG, Bohnert HJ, Griffiths H (1998) Growth and development of Mesembryanthemum crystallinum (Aizoaceae). New Phytol 138:171-190

Ali Z, Park HC, Ali A, Oh DH, Aman R, Kropornicka A, Hong H, Choi W, Chung WS, Kim WY, Bressan RA, Bohnert HJ, Lee SY, Yun DJ (2012) TsHKT1;2, a HKT1 homolog from the extremophile Arabidopsis-relative Thellungiella salsuginea, shows $\mathrm{K}^{+}$-specificity in the presence of $\mathrm{NaCl}$. Plant Physiol 158:1463-1474

Allaby RG, Fuller DQ, Brown TA (2008) The genetic expectations of a protracted model for the origins of domesticated crops. Proc Natl Acad Sci USA 105:13982-13986

Aronson JA (1989) HALOPH: a data base of salt tolerant plants of the world. Arid land studies. University of Arizona, Tucson

Ayers RS, Westcot DW (1985) Water quality for agriculture. Fao Irrigation and Drainage Paper 29 (Rev. 1). Food and Agriculture Organization (FAO) of the United Nations. Rome

Balsamo RA, Thomson WW (1993) Ultrastructural features associated with secretion in the salt glands of Frankenia grandifolia (Frankeniaceae) and Avicennia germinans (Avicenniaceae). Am J Bot 80:1276-1283

Balsamo RA, Thomson WW (1996) Isolation of mesophyll and secretory cell protoplasts of the halophyte Ceratostigma plumbaginoides (L.): a comparison of ATPase concentration and activity. Plant Cell Rep 15:418-422

Bertorello AM, Zhu JK (2009) SIK1/SOS2 networks: decoding sodium signals via calcium-responsive protein kinase pathways. Pflugers Arch Eur J Physiol 458:613-619

Bohnert HJ, Cushman JC (2000) The ice plant cometh—models for environmental stress tolerance. J Plant Growth Regul 19:334-346

Breckle S-W (2002) Walter's vegetation of the earth: the ecological systems of the geo-biosphere. Springer, Berlin

Bressan RA, Zhang C, Zhang H, Hasegawa PM, Bohnert HJ, Zhu JK (2001) Learning from the Arabidopsis experience. The next gene search paradigm. Plant Physiol 127:1354-1360

Cannon SB, Mitra A, Baumgarten A, Young ND, May G (2004) The roles of segmental and tandem gene duplication in the evolution of large gene families in Arabidopsis thaliana. BMC Plant Biol 4:10

Cao J, Schneeberger K, Ossowski S, Günther T, Bender S, Fitz J, Koenig D, Lanz C, Stegle O, Lippert C, Wang X, Ott F, Müller J, Alonso-Blanco C, Borgwardt K, Schmid KJ, Weigel D (2011) Whole-genome sequencing of multiple Arabidopsis thaliana populations. Nat Genet 43:956-963
Chen ZJ, Wang J, Tian L, Lee HS, Wang JJ, Chen M, Lee JJ, Josefsson C, Madlung A, Watson B, Lippman Z, Vaughn M, Pires JC, Colot V, Doerge RW, Martienssen RA, Comai L, Osborn TC (2004) The development of an Arabidopsis model system for genome-wide analysis of polyploidy effects. Biol J Linn Soc 82:689-700

Conrad DF, Pinto D, Redon R, Feuk L, Gokcumen O, Zhang Y, Aerts J, Andrews TD, Barnes C, Campbell P, Fitzgerald T, Hu M, Ihm CH, Kristiansson K, Macarthur DG, Macdonald JR, Onyiah I, Pang AW, Robson S, Stirrups K, Valsesia A, Walter K, Wei J; Wellcome Trust Case Control Consortium, Tyler-Smith C, Carter NP, Lee C, Scherer SW, Hurles ME (2010) Origins and functional impact of copy number variation in the human genome. Nature 464:704-712

Cushman JC (2001) Osmoregulation in plants: implications for agriculture. Am Zool 41:758-769

Cushman JC, Bohnert HJ (1999) Crassulacean acid metabolism: molecular genetics. Annu Rev Plant Physiol Plant Mol Biol 50:305-332

Dalton FN, Maggio A, Piccinni G (2000) Simulation of shoot chloride accumulation: separation of physical and biochemical processes governing plant salt tolerance. Plant Soil 219:1-11

Dassanayake M, Oh DH, Haas J, Hernandez AG, Ali S, Hong H, Yun DJ, Bressan RA, Zhu J-K, Bohnert HJ, Cheeseman JM (2011a) The genome sequence of an extremophile Arabidopsis-relative: Thellungiella parvula. Nat Genet 43:913-918

Dassanayake M, Oh DH, Hong H, Bohnert HJ, Cheeseman JM (2011b) Importance of transcription control for halophytic life. Trends Plant Sci 16:1-3

Deng Z, Li Y, Xia R, Wang W, Huang X, Zhang L, Zhang S, Yang C, Zhang Y, Chen M, Xie Q (2009) Structural analysis of 83-kb genomic DNA from Thellungiella halophila: sequence features and micro-colinearity between salt cress and Arabidopsis thaliana. Genomics 94:324-332

Farnsworth E (2004) Hormones and shifting ecology throughout plant development. Ecology 85:5-15

Flowers TJ (2004) Improving crop salt tolerance. J Exp Bot $55: 307-319$

Flowers TJ, Colmer TD (2008) Salinity tolerance in halophytes. New Phytol 179:945-963

Flowers T, Yeo A (1995) Breeding for salinity resistance in crop plants: where next? Aust J Plant Physiol 22:875-884

Flowers TJ, Troke PF, Yeo AR (1977) The mechanism of salt tolerance in halophytes. Annu Rev Plant Physiol 28:89-121

Flowers TJ, Hajibagheri MA, Clipson NJW (1986) Halophytes. Q Rev Biol 61:313-337

Franzke A, Lysak MA, Al-Shehbaz IA, Koch MA, Mummenhoff K (2011) Cabbage family affairs: the evolutionary history of Brassicaceae. Trends Plant Sci 16:108-116

Freeling M (2009) Bias in plant gene content following different sorts of duplication: tandem, whole-genome, segmental, or by transposition. Annu Rev Plant Biol 60:433-453

Freitas H, Breckle S-W (1992) Importance of bladder hairs for salt tolerance of field-grown Atriplex species from a Portuguese salt marsh. Flora 187:283-297

Glenn EP (1987) Relationship between cation accumulation and water content of salt tolerant grasses and a sedge. Plant Cell Environ 10:205-212

Glenn EP, O’Leary J (1984) Relationship between salt accumulation and water content of dicotyledonous halophytes. Plant Cell Environ 7:253-261

Glenn E, Miyamoto S, Moore D, Brown J, Thompson T, Brown P (1985) Water requirements for cultivating Salicornia bigelovii Torr. with seawater on sand in a coastal desert environment. J Arid Environ 36:711-730 
Glenn E, O’Leary J, Watson M, Thompson T, Kuehl R (1991) Salicornia bigelovii Torr.: an oilseed halophyte for seawater irrigation. Science 251:1065-1067

Glenn EP, Watson MC, O'Leary JW, Axelson RD (1992) Comparison of salt tolerance and osmotic adjustment of low-sodium and high-sodium subspecies of the $\mathrm{C} 4$ halophyte, Atriplex canescens. Plant Cell Environ 15:711-718

Glenn EP, Brown JJ, Blumwald E (1999) Salt tolerance and crop potential of halophytes. Crit Rev Plant Sci 18:227-255

Gong Q, Li P, Ma S, Rupassara SI, Bohnert HJ (2005) Salinity stress adaptation competence in the extremophile Thellungiella halophila in comparison with its relative Arabidopsis thaliana. Plant J 44:826-839

Greenway H (1968) Growth stimulation by high chloride concentrations in halophytes. Isr J Bot 17:169-177

Greenway H, Munns R (1980) Mechanisms of salt tolerance in nonhalophytes. Annu Rev Plant Physiol 31:149-190

Hu TT, Pattyn P, Bakker EG, Cao J, Cheng JF, Clark RM, Fahlgren N, Fawcett JA, Grimwood J, Gundlach H, Haberer G, Hollister JD, Ossowski S, Ottilar RP, Salamov AA, Schneeberger K, Spannagl M, Wang X, Yang L, Nasrallah ME, Bergelson J, Carrington JC, Gaut BS, Schmutz J, Mayer KF, Van de Peer Y, Grigoriev IV, Nordborg M, Weigel D, Guo YL (2011) The Arabidopsis lyrata genome sequence and the basis of rapid genome size change. Nat Genet 43:476-481

Inan G, Zhang H, Li P, Wang Z, Cao Z, Zhang C, Quist TM, Goodwin SM, Zhu J, Shi H, Damsz B, Charbaji T, Gong Q, Ma S, Fredricksen M, Galbraith DW, Jenks MA, Rhodes D, Hasegawa PM, Bohnert HJ, Joly RJ, Bressan RA, Zhu JK (2004) Salt cress. A halophyte and cryophyte Arabidopsis relative model system and its applicability to molecular genetic analyses of growth and development of extremophiles. Plant Physiol 135:1718-1737

Ito $\mathrm{H}$, Gaubert $\mathrm{H}$, Bucher E, Mirouze M, Vaillant I, Paszkowski J (2011) An siRNA pathway prevents transgenerational retrotransposition in plants subjected to stress. Nature 472:115-119

Kato T, Emi M, Sato H, Arawaka S, Wada M, Kawanami T, Katagiri T, Tsuburaya K, Toyoshima I, Tanaka F, Sobue G, Matsubara K (2010) Segmental copy-number gain within the region of isopentenyl diphosphate isomerase genes in sporadic amyotrophic lateral sclerosis. Biochem Biophys Res Commun 402:438-442

Kawasaki S, Borchert C, Deyholos M, Wang H, Brazille S, Kawai K, Galbraith D, Bohnert HJ (2001) Gene expression profiles during the initial phase of salt stress in rice. Plant Cell 13:889-905

Kramer PJ (1984) Problems in water relations of plants and cells. In: Kramer PJ (ed) International review of cytology, pp 254-286

Kreeb K (1974) Pflanzen an Salzstandorten. Naturwissenschaften 61:337-343

Kvitek DJ, Will JL, Gasch AP (2008) Variations in stress sensitivity and genomic expression in diverse $S$. cerevisiae isolates. PLoS Genet 4:e1000223

Le Houerou HN (1993) Salt-tolerant plants for the arid regions of the Mediterranean isoclimatic zone. In: Lieth $\mathrm{H}$, Masoom A (eds) Towards the rational use of high salinity tolerant plants, vol 1 . Kluwer Academic Publishers, Dordrecht, pp 403-422

Liphschitz N, Waisel Y (1982) Adaptation of plants to saline environments: salt excretion and glandular structure. In: Sen D, Rajpurohit K (eds) Tasks for vegetation science. Dr. W. Junk, The Hague, pp 197-214

Luo M, Liu X, Singh P, Cui Y, Zimmerli L, Wu K (2012) Chromatin modifications and remodeling in plant abiotic stress responses. Biochim Biophys Acta 1819:129-136

Maggio A, Zhu JK, Hasegawa PM, Bressan RA (2006) Osmogenetics: Aristotle to Arabidopsis. Plant Cell 18:1542-1557

Maggio A, Raimondi G, Martino A, De Pascale S (2007) Salt stress response in tomato beyond the salinity tolerance threshold. Environ Exp Bot 59:276-282
Mandáková T, Lysak MA (2008) Chromosomal phylogeny and karyotype evolution in $x=7$ crucifer species (Brassicaceae). Plant Cell 20:2559-2570

Mata-González R, Meléndez-González R, Martínez-Hernández JJ (2001) Aerial biomass and elemental changes in Atriplex canescens and A. acanthocarpa as affected by salinity and soil water availability. USDA Forest Service Proc RMRS-P-21, pp 308-311

Munns R (2002) Comparative physiology of salt and water stress. Plant Cell Environ 25:239-250

Oh DH, Leidi E, Zhang Q, Hwang SM, Li Y, Quintero FJ, Jiang X, D'Urzo MP, Lee SY, Zhao Y, Bahk JD, Bressan RA, Yun DJ, Pardo JM, Bohnert HJ (2009) Loss of halophytism by interference with SOS1 expression. Plant Physiol 151:210-222

Oh DH, Dassanayake M, Kropornika A, Paino d'Urzo M, Lambert G, Galbraith DW, Bressan RA, Zhu JK, Yun DJ, Cheeseman JM, Bohnert HJ (2010) Chromosome structures of the extreme halophyte Thellungiella parvula distinguished from Thellungiella salsuginea (T. halophila) and Arabidopsis thaliana. Plant Physiol 154:1040-1052

Ohno S (1970) Evolution by gene duplication. Springer, Berlin

Oo KS, Lang NT (2005) Developing salt tolerance in rice by mutagenesis. Omonrice 13:126-134

Orsini F, Paino D'Urzo M, Inan G, Serra S, Oh D-H, Mickelbart MV, Consiglio F, Li X, Jeong JC, Yun D-J, Bohnert HJ, Bressan RA, Maggio A (2010) Emerging new Arabidopsis-relative model systems (ARMS): a comparative study of salt tolerance parameters in eleven wild relatives of Arabidopsis thaliana. J Exp Bot 61:3787-3798

Orsini F, Accorsi M, Gianquinto G, Dinelli G, Antognoni F, Ruiz Carrasco K, Martinez E, AlNayef M, Marotti I, Bosi S, Biondi S (2011) Beyond the ionic and osmotic response to salinity in Chenopodium quinoa: functional elements of successful halophytism. Funct Plant Biol 38:818-831

Osmond CB, Bjorkman 0, Anderson DJ (1980) Physiological processes in plant ecology: towards a synthesis with Atriplex. In: Ecological studies, vol 36. Springer, New York

Popp M (1995) Salt resistance in herbaceous halophytes and mangroves. Prog Bot 56:416-429

Popp M, Albert R (1995) The role of organic solutes in salinity adaptation of mangroves and herbaceous halophytes In: Ajmal Khan M, Ungar IA (eds) Biology of salt tolerant plants. University of Karachi, Pakistan, pp 139-149

Prochnik S, Marri PR, Desany B, Rabinowicz PD, Kodira C, Mohiuddin M, Rodriguez F, Fauquet C, Tohme J, Harkins T, Rokhsar DS, Rounsley S (2012) The cassava genome: current progress, future directions. Trop Plant Biol, pp 1-7 (epub 5 January 2012)

Redondo-Gómez S, Mateos-Naranjo E, Davy AJ, Fernández-Muñoz F, Castellanos EM, Luque T, Figueroa ME (2007) Growth and photosynthetic responses to salinity of the salt-marsh shrub Atriplex portulacoides. Ann Bot 100:555-563

Rensing SA, Lang D, Zimmer AD et al (2008) The Physcomitrella genome reveals evolutionary insights into the conquest of land by plants. Science 319:64-69

Rindos D (1987) The origins of agriculture: an evolutionary perspective. Academic Press, Orlando

Rodgers-Melnick E, Mane SP, Dharmawardhana P, Slavov GT, Crasta OR, Strauss SH, Brunner AM, Difazio SP (2012) Contrasting patterns of evolution following whole genome versus tandem duplication events in Populus. Genome Res 22:95-105

Sanders D (2000) Plant biology: the salty tale of Arabidopsis. Curr Biol 10:486-488

Schirmer U, Breckle S-W (1982) The role of bladders for salt removal in some Chenopodiaceae (mainly) Atriplex species. In: Sen DN, 
Rajpurohit KS (eds) T:VS 2 (tasks for vegetative science 2) contributions to the ecology of halophytes. Dr. W. Junk Publishers, Hague, pp 215-231

Serrano R (1996) Salt tolerance in plants and microorganisms: toxicity targets and defense responses. Int Rev Cytol 165:1-52

Swanson-Wagner RA, Eichten SR, Kumari S, Tiffin P, Stein JC, Ware D, Springer NM (2010) Pervasive gene content variation and copy number variation in maize and its undomesticated progenitor. Genome Res 20:1689-1699

Tarasoft CS, Mallory-Smith CA, Ball DA (2007) Comparative plant responses of Puccinellia distans and Puccinellia nuttalliana to sodic versus normal soil types. J Arid Environ 70:403-417

Tuskan GA, Di Fazio S, Jansson S et al (2006) The genome of black cottonwood, Populus trichocarpa (Torr. \& Gray). Science 313:1596-1604

Ungar IA, Pfeiffer CJ (1991) Ecophysiology of vascular halophytes. CRC Press, Boca Raton, p 209

Varshney RK, Chen W, Li Y, Bharti AK, Saxena RK, Schlueter JA, Donoghue MT, Azam S, Fan G, Whaley AM, Farmer AD, Sheridan J, Iwata A, Tuteja R, Penmetsa RV, Wu W, Upadhyaya HD, Yang SP, Shah T, Saxena KB, Michael T, McCombie WR, Yang B, Zhang G, Yang H, Wang J, Spillane C, Cook DR, May GD, Xu X, Jackson SA (2011) Draft genome sequence of pigeonpea (Cajanus cajan), an orphan legume crop of resourcepoor farmers. Nat Biotechnol 30:83-89

Volkov V, Amtmann A (2006) Thellungiella halophila, a salt-tolerant relative of Arabidopsis thaliana, has specific root ion-channel features supporting $\mathrm{K}^{+} / \mathrm{Na}^{+}$homeostasis under salinity stress. Plant J 48:342-353

Walia H, Wilson C, Condamine P, Liu X, Ismail AM, Zeng L, Wanamaker SI, Mandal J, Xu J, Cui X, Close TJ (2005) Comparative transcriptional profiling of two contrasting rice genotypes under salinity stress during the vegetative growth stage. Plant Physiol 139:822-835

Wang W, Wu Y, Li Y, Xie J, Zhang Z, Deng Z, Zhang Y, Yang C, Lai J, Zhang H, Bao H, Tang S, Yang C, Gao P, Xia G, Guo H, Xie Q (2010) A large insert Thellungiella halophila BIBAC library for genomics and identification of stress tolerance genes. Plant Mol Biol 72:91-99

Waszak SM, Hasin Y, Zichner T, Olender T, Keydar I, Khen M, Stütz AM, Schlattl A, Lancet D, Korbel JO (2010) Systematic inference of copy-number genotypes from personal genome sequencing data reveals extensive olfactory receptor gene content diversity. PLoS Comput Biol 6:e1000988

Waterhouse RM, Zdobnov EM, Kriventseva EV (2011) Correlating traits of gene retention, sequence divergence, duplicability and essentiality in vertebrates, arthropods, and fungi. Genome Biol Evol 3:75-86

Yang HM, Zhang JH, Zhang XY (2005) Regulation mechanisms of stomatal oscillation. J Integr Plant Biol 47:1159-1172

Zhu JK (2000) Genetic analysis of plant salt tolerance using Arabidopsis. Plant Physiol 124:941-948

Zhu JK (2001) Plant salt tolerance. Trends Plant Sci 6:66-71 